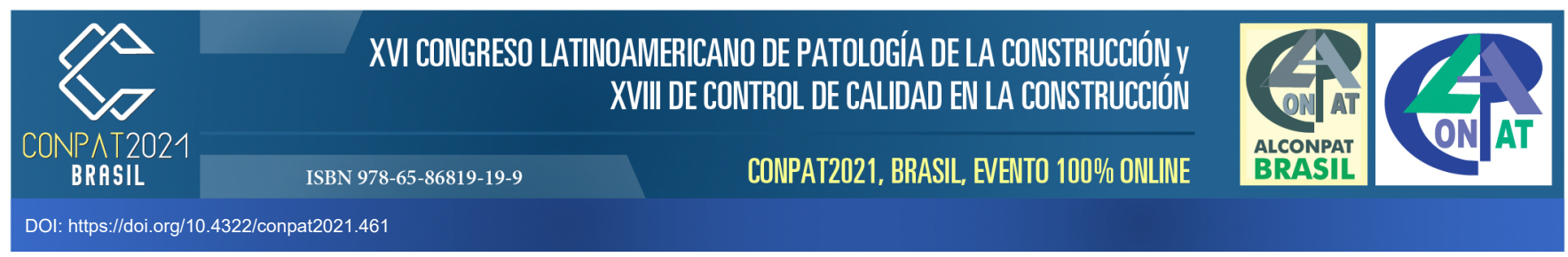

\title{
ANÁLISE DE MANIFESTAÇÕES PATOLÓGICAS EM SISTEMAS DE PAREDES DE CONCRETO MOLDADAS in loco
}

\author{
$\underline{\text { F. M. Padilha }}^{1}$, L. R. S. Carneiro ${ }^{1 *}$, J. C. Santos ${ }^{1}$, F. S. J. Poggiali ${ }^{1}$ \\ *Autor para Contato: carneirola@hotmail.com \\ ${ }^{1}$ Departamento de Engenharia Civil, Centro Federal de Educação Tecnológica de Minas Gerais, Av. Amazonas, \\ 7675 - Nova Gameleira, Belo Horizonte - MG, Brasil, 30510-000
}

\begin{abstract}
RESUMO
Este trabalho analisou as manifestações patológicas de duas obras em sistema construtivo de paredes de concreto. Por se tratar de um sistema construtivo ainda incipiente no Brasil, o conhecimento prévio de possíveis falhas pode ajudar novos construtores na prevenção de patologias em obras futuras. Após identificação das anomalias, foi feito o levantamento das causas, diagnóstico e proposição de tratamento. $\mathrm{O}$ estudo identificou descolamento cerâmico, fissuras nos elementos estruturais, segregação do concreto, vazios de concretagem e cobrimento insuficiente das armaduras. A principal origem das anomalias foi a etapa de execução, sendo necessária a implantação de um rigoroso treinamento da mão-de-obra, aliado à contínua fiscalização dos serviços. A concretagem também deve ser previamente planejada, sendo fundamental a participação síncrona dos diferentes agentes envolvidos. O estudo enfatiza a importância da realização de fiscalizações contínuas, que proporcionem aprendizado e melhorias, a fim de que erros cometidos no passado não se repitam no futuro.
\end{abstract}

Palavras-chave: patologia das construções; manifestações patológicas; paredes de concreto; estudo de caso.

\begin{abstract}
This work analyzed the pathological manifestations of two different constructions, made with concrete wall systems. Considering that this system is not well known in Brazil yet, prior knowledge of possible failures may help new builders on preventing pathologies in future buildings. A survey of the causes was made, followed by diagnosis and treatment proposals. Ceramic detachment, cracks in structural elements, concrete segregation, concrete voids and insufficient reinforcement cover were identified. The main cause of the anomalies was the execution stage, highlighting the importance of a rigorous training of the workforce, combined with continuous service inspection. The concreting stage must also be previously planned, and the synchronous participation of the different agents involved is essential. Continuous inspections are encouraged in order to provide learning and improvements, so that mistakes made in the past are not repeated in the future.
\end{abstract}


Keywords: building pathologies; pathological manifestaciones; concrete walls system; case study.

\section{RESUMEN}

Este trabajo analizó las manifestaciones patológicas de dos obras en sistema constructivo de paredes de hormigón. Por se tratar de um sistema construtivo ainda incipiente no Brasil, o conhecimento prévio de possíveis falhas pode ajudar novos construtores na prevenção de patologias em obras futuras. Tras la identificación de las anomalías, se hizo un estudio de las causas, diagnóstico y proposición de tratamiento. El estudio identificó desprendimiento cerámico, físuras en los elementos estructurales, segregación del hormigón, vacíos de hormigonado y cubrimiento insuficiente de las armaduras. El principal origen de las anomalías fue a la etapa de ejecución, siendo necesario implantar riguroso entrenamiento de la mano de obra, aliado a la continua fiscalización de los servicios. El hormigonado debe ser previamente planificado, siendo fundamental la participación síncrona de los diferentes agentes involucrados. Se fomenta la realización de controles que proporcionen aprendizaje y mejoras, a fin de que errores cometidos en el pasado no se repitan en el futuro.

Palabras clave: patología de las construcciones; manifestaciones patológicas; paredes de hormigón; estudio de caso.

\section{INTRODUÇÃO}

O rápido desenvolvimento da urbanização brasileira no começo do século XXI gerou muitas oportunidades para o setor da construção civil, o qual se viu estimulado a otimizar seus sistemas construtivos, a fim de reduzir custos e diminuir o prazo das construções (ABCP, 2008). O sistema construtivo de paredes de concreto surgiu nas décadas de 1970 e 1980, mas só ganhou relevância a partir dos anos 2000 (Misurelli e Massuda, 2009). No ano de 2007, verificou-se um aumento significativo de edificações construídas pelo sistema parede de concreto, motivados pelo surgimento dos programas sociais, como o Programa Minha Casa, Minha Vida (PMCMV), quando se observou uma crescente demanda por edificações de teor social (Braguim e Bittencourt, 2014).

Em 2012, a Associação Brasileira de Normas Técnicas (ABNT) publicou a NBR 16.055 - Parede de Concreto Moldada no Local para a Construção de Edificações - Requisitos e Procedimentos, cujo objetivo é estabelecer os requisitos para a construção de edificações com o sistema parede de concreto moldado in loco. Ela define parede de concreto como um elemento estrutural autoportante, moldado no local, com comprimento dez vezes maior que sua espessura, capaz de suportar cargas no mesmo plano da parede. O sistema consiste, inicialmente, na montagem das armações e instalações elétricas e hidráulicas, seguidas da montagem das fôrmas e da concretagem (Dornelles e Oliveira, 2012). Segundo a Associação Brasileira de Cimento Portland (ABCP, 2008), as fôrmas utilizadas podem ser metálicas, metálicas com compensado e plásticas, ficando a escolha a cargo da necessidade da obra e disponibilidade de recursos e materiais. A escolha do concreto, por sua vez, determina a qualidade e a efetividade do sistema monolítico. De certa maneira, todos os concretos empregados neste subsistema são especiais, uma vez que necessitam de aditivos para atender a diferentes requisitos, como o tempo de desforma, por exemplo (Monge, 2013). 
O sistema construtivo de paredes de concreto não visa diretamente a economia em materiais, mas a redução do tempo de construção e consequentes gastos com mão-de-obra, aluguel de máquinas e equipamentos, além de custos com instalações provisórias (Dornelles e Oliveira, 2012). Contudo, este sistema apresenta vantagens em relação aos sistemas convencionais de construção. Dentre estas, pode-se citar maior produtividade, maior controle tecnológico dos insumos, racionalização e industrialização dos processos, baixa geração de resíduo, dentre outras. Porém, devido ao custo da fôrma e a necessidade de uma mão-de-obra especializada, este tipo de construção é viabilizada para projetos padronizados e com repetições (Côrrea, 2012). Ressaltase, ainda, a importância de se realizar inspeções contínuas dos serviços, a fim de se evitar retrabalhos e possíveis patologias devido a procedimentos mal executados.

O presente artigo visa analisar as manifestações patológicas de duas obras que fizeram uso do sistema construtivo paredes de concreto moldadas in loco. Além disso, foi feito o levantamento das causas das anomalias, com os diagnósticos e a proposição de possíveis tratamentos.

\section{METODOLOGIA}

Para o desenvolvimento do presente trabalho, foram realizados estudos de caso em duas obras, denominadas Obra A e Obra B, ambas pertencentes ao Programa Minha Casa, Minha Vida (PMCMV). Os empreendimentos consistem em condomínios residenciais multifamiliares com 4 pavimentos e 4 apartamentos por andar cada. A Obra B teve início após o término da Obra A, tendo grande parte da mão-de-obra sido mobilizada de uma para a outra. O Quadro 1 resume as principais características das obras analisadas.

Quadro 1. Características gerais das Obras A e B.

\begin{tabular}{|l|l|l|}
\hline \multicolumn{1}{|c|}{ Detalhes Técnicos } & \multicolumn{1}{|c|}{ Obra A } & \multicolumn{1}{c|}{ Obra B } \\
\cline { 1 - 2 } Número de Unidades & 288 & 144 \\
\hline Método Construtivo & Parede de Concreto & Parede de Concreto \\
\cline { 1 - 2 } Prazo de Obra & 15 meses & $80 \%$ \\
\hline Status da Obra (Janeiro/2021) & Finalizada & $23.115 \mathrm{~m}^{2}$ \\
\hline Área Construída & $28.948 \mathrm{~m}^{2}$ & $45,46 \mathrm{~m}^{2}$ \\
\hline Área por Unidade & $42,48 \mathrm{~m}^{2}$ & $\begin{array}{l}\text { Forma monolítica tipo vagão } \\
\text { (produtividade de 2 } \\
\text { apartamentos por dia). Uma } \\
\text { parte era forma utilizada pela } \\
\text { primeira vez e a outra parte } \\
\text { foi reaproveitada da Obra A. }\end{array}$ \\
\hline & $\begin{array}{l}\text { Forma monolítica tipo vaga Utilizada } \\
\text { (produtividade de 2 } \\
\text { apartamentos por dia). Forma } \\
\text { utilizada pela primeira vez. }\end{array}$ & \multicolumn{2}{|l}{} \\
\hline
\end{tabular}

O concreto especificado para ambas as obras apresenta resistência à compressão $\left(\mathrm{f}_{\mathrm{ck}}\right)$ igual a $25 \mathrm{MPa}$, Slump de $22 \pm 3 \mathrm{~cm}$, fator água/cimento $\leq 60$ e adição de fibras $\geq 300$ gramas $/ \mathrm{m}^{3}$. Os traços do concreto das Obras A e B são apresentados nas Tabelas 1 e 2, respectivamente. 
Tabela 1. Traço do concreto utilizado na Obra A.

\begin{tabular}{|l|l|l|}
\hline Componentes & Insumos & Peso/m \\
\hline Cimento & CPV ARI RS & $320 \mathrm{~kg}$ \\
\hline Agregado Miúdo I & Areia Natural Rio Fina & $305 \mathrm{~kg}$ \\
\hline Agregado Miúdo II & Areia Artificial Calcário Média & $742 \mathrm{~kg}$ \\
\hline Agregado Graúdo & Brita 0 Gnaisse & $800 \mathrm{~kg}$ \\
\hline Aditivo I & Polifuncional & $1,20 \mathrm{~kg}$ \\
\hline Aditivo II & Mid Range & $1,5 \mathrm{~kg}$ \\
\hline Aditivo III & Inibidor de Hidratação & $0,350 \mathrm{~kg}$ \\
\hline Água & - & 1901 \\
\hline
\end{tabular}

Tabela 2. Traço do concreto utilizado na Obra B.

\begin{tabular}{|l|l|l|}
\hline Componentes & Insumos & Peso/m \\
\hline Cimento & CPV ARI & $330 \mathrm{~kg}$ \\
\hline Agregado Miúdo I & Areia Natural Rio Fina & $548 \mathrm{~kg}$ \\
\hline Agregado Miúdo II & Areia Artificial Calcário Média & $548 \mathrm{~kg}$ \\
\hline Agregado Graúdo & Brita 0 Gnaisse & $748 \mathrm{~kg}$ \\
\hline Aditivo & Viscoflow 35 SIKA Superplastificante & $4,28 \mathrm{~kg}$ \\
\hline Água & - & 1981 \\
\hline
\end{tabular}

\subsection{Coleta e Análise dos Dados}

Os dados foram coletados in loco durante o período de execução das obras. Diversos documentos como fotos, vídeos e documentos técnicos (fichas de Verificação de Serviço, laudos de Rompimento de Concreto e Instrução de Serviços) foram analisados para coleta de informações. Em seguida, aplicou-se a metodologia apresentada no fluxograma da Figura 1 para o desenvolvimento do trabalho.

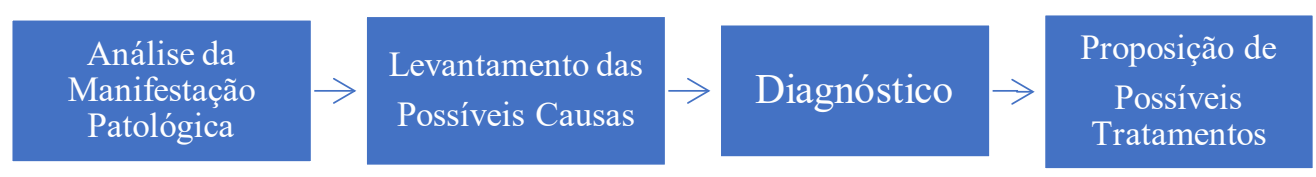

Figura 1. Metodologia de Análise das Manifestações Patológicas verificadas nos sistemas de paredes de concreto moldadas in loco nas Obras A e B.

\section{RESULTADOS E DISCUSSÕES}

Após análise detalhada das duas obras, foram identificadas as seguintes anomalias: descolamento de peças cerâmicas, fissuras no concreto das paredes e lajes, segregação do concreto e vazios de concretagem e espessura insuficiente do cobrimento das armaduras. Cada uma delas será detalhada nos subtópicos seguintes. 


\subsection{Descolamento de Revestimento Cerâmico}

Durante a etapa de check list foram observados descolamento do revestimento cerâmico dos pisos e de paredes na Obra A. Foram realizados ensaios de percussão nos pisos e nas paredes revestidos de sete blocos aleatórios desta Obra, cujos resultados são apresentados nas Figuras 2 e 3 . Notase que o Bloco 3 apresentou um maior número de peças cerâmicas soltas. Neste sentido, é importante comentar que este Bloco possuía estrutura diferente dos demais, sendo formado por apartamentos para pessoas com deficiência (PCD). Portanto, neste Bloco os ciclos de concretagem atrasaram e os serviços de acabamento foram realizados considerando-se um tempo de cura menor (cerca de 3 dias), tanto do concreto dos elementos estruturais, como da impermeabilização.

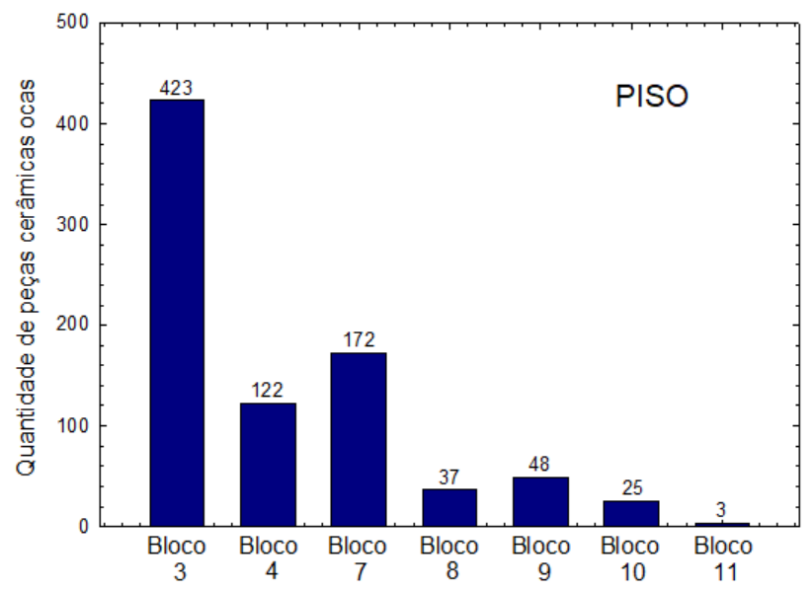

Figura 2. Total de peças cerâmicas descoladas em áreas de piso de sete blocos diferentes e aleatórios da Obra A.

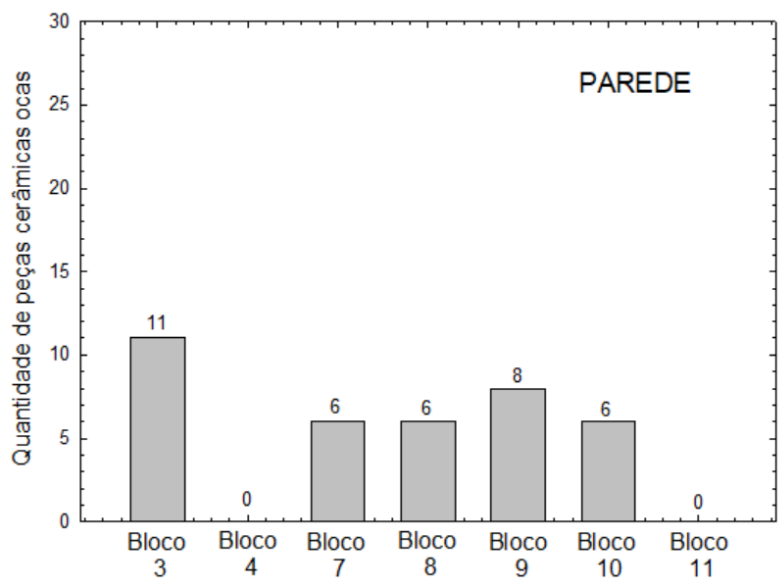

Figura 3. Total de peças cerâmicas descoladas em áreas de parede de sete blocos diferentes e aleatórios da Obra A.

A partir da análise visual das peças cerâmicas soltas, concluiu-se que grande parte dos descolamentos se deu entre a argamassa polimérica (impermeabilização) e a laje, ou entre a argamassa polimérica e a argamassa colante ACII. O último caso é ilustrado pela Figura 4. Fica 
evidente que a espessura da argamassa colante encontrada na obra é superior àquela especificada pela NBR 13753 (ABNT, 1996), a qual se limita entre 0,3 a $0,4 \mathrm{~mm}$.

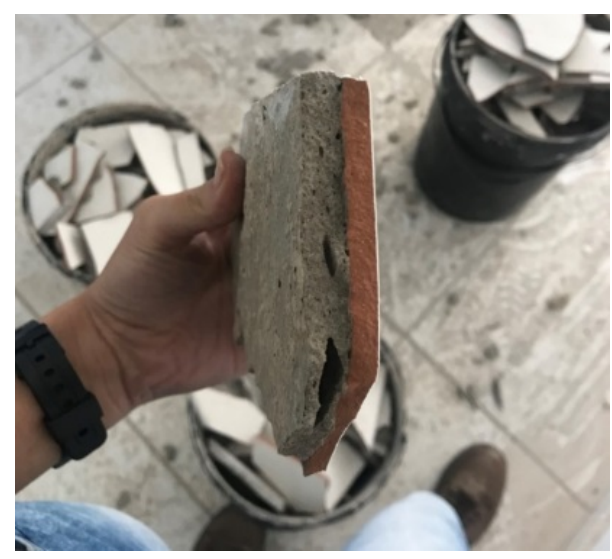

Figura 4. Descolamento entre a argamassa colante ACII e a argamassa polimérica em um piso de banheiro da Obra A.

A fim de corroborar com a análise visual, foram realizados ensaios de arrancamento nas peças cerâmicas de piso e de parede da Obra A, conforme preconizado pela NBR 13528 (ABNT, 1995). Os resultados revelaram que houve ruptura entre a argamassa colante ACII e o substrato, o qual era a laje ou parede de concreto, no caso das salas; a argamassa polimérica, no caso dos banheiros e áreas de serviço; e a emulsão acústica emborrachada, no caso dos quartos. O gráfico da Figura 5 mostra os valores de resistência à tração dos ensaios de arrancamento realizados nos diferentes substratos. Nota-se que apenas o revestimento cerâmico assentado sobre o substrato de concreto, localizado nas paredes e pisos das salas, apresentou resistência à tração acima da mínima prevista pela NBR 14081 (ABNT, 2005), a qual é de 0,50 MPa e está representada no gráfíco pela linha vermelha. Neste caso, o revestimento em questão alcançou resistência de $0,57 \mathrm{MPa}$, contra 0,19 $\mathrm{MPa}$ do revestimento assentado sobre argamassa polimérica, localizado nos banheiros e áreas de serviço, e 0,22 MPa daquele assentado sobre emulsão acústica emborrachada, localizado nos quartos.

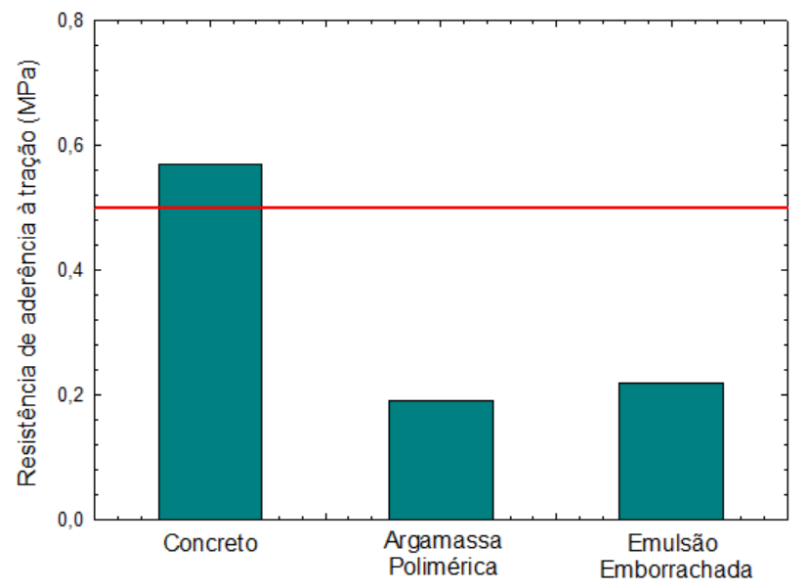

Figura 5. Resistência média de aderência à tração entre a argamassa colante AC-II e os três substratos distintos. 


\subsubsection{Causas}

As prováveis causas do descolamento das peças cerâmicas na Obra A são: o excesso de argamassa colante utilizado no assentamento, com a equivocada finalidade de regularizar a superfície do substrato; a cura insuficiente do concreto e da argamassa polimérica, esta última no caso de áreas molháveis; e a limpeza inadequada do substrato que receberia o revestimento, neste caso, a impermeabilização e a proteção acústica. A presença de sujeira, constatada nas superfícies de ambos os substratos, prejudicou a aderência da argamassa colante.

\subsubsection{Diagnóstico}

O descolamento cerâmico é considerado uma anomalia de grau crítico, pois oferece risco à segurança dos usuários, além de interferir na estética do meio ambiente. A ausência da placa cerâmica comprometerá, ainda, a estanqueidade dos ambientes molháveis.

\subsubsection{Tratamento}

O tratamento indicado para a Obra A inclui a realização de ensaios de percussão em todos os blocos do empreendimento, a fim de mapear as cerâmicas ocas. Uma vez identificadas, tais peças devem ser removidas, prosseguindo-se à correta limpeza do substrato. A limpeza consiste em dois processos: remoção e lavagem. Para remover as impurezas, pulverulência, eflorescências e mofo usam-se uma broxa ou escova de fio de aço e em seguida faz-se a lavagem com água pressurizada ou mangueira. Posteriormente, deve ser feito o assentamento da peça cerâmica, respeitando-se a espessura de argamassa colante prevista por norma, entre 0,3 e 0,4 $\mathrm{mm}$ e realizando-se a dupla colagem, quando do caso de peças com dimensões superiores a 30x30 cm. Por ter sido executada posteriormente à Obra $\mathrm{A}$, a Obra $\mathrm{B}$ contou com um rigoroso controle de execução, com cura adequada do substrato e regularização de sua superfície, além de limpeza profunda deste substrato e controle da espessura de assentamento. Transcorridos 28 dias de cura da argamassa colante, realizou-se o ensaio de percussão em três blocos da obra B. Constatou-se que nenhuma peça cerâmica se encontrava solta.

\subsection{Fissuras no Concreto das Paredes e Lajes}

Em ambas as obras, os elementos estruturais paredes e lajes apresentaram fissuras superficiais. As anomalias apresentavam abertura inferior a $0,4 \mathrm{~mm}$, sendo observadas em cantos de parede, em cantos de janelas e em grandes panos de parede, sobretudo nos apartamentos do $1^{\mathrm{o}}$ pavimento. A Figura 6 apresenta exemplos de fissuras encontradas nas paredes da Obra A.

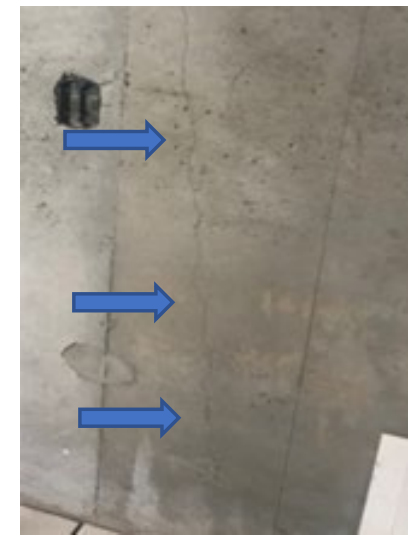

(a)

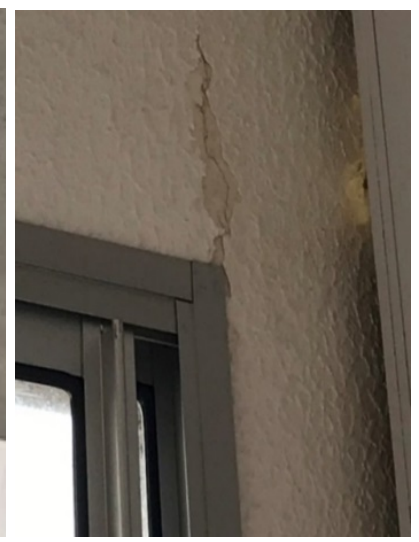

(b) 
Figura 6. Fissura ao longo da extensão de parede de concreto (a) e fissura no canto superior de janela de parede de concreto (b), ambas na Obra A.

Além das fissuras citadas na Figura 6, foram observadas, ainda, fissuras com o formato de mapas em algumas lajes de ambas as obras, de maneira especial em lajes concretadas em dias muito quentes. A Figura 7 ilustra tal anomalia verificada na Obra B.

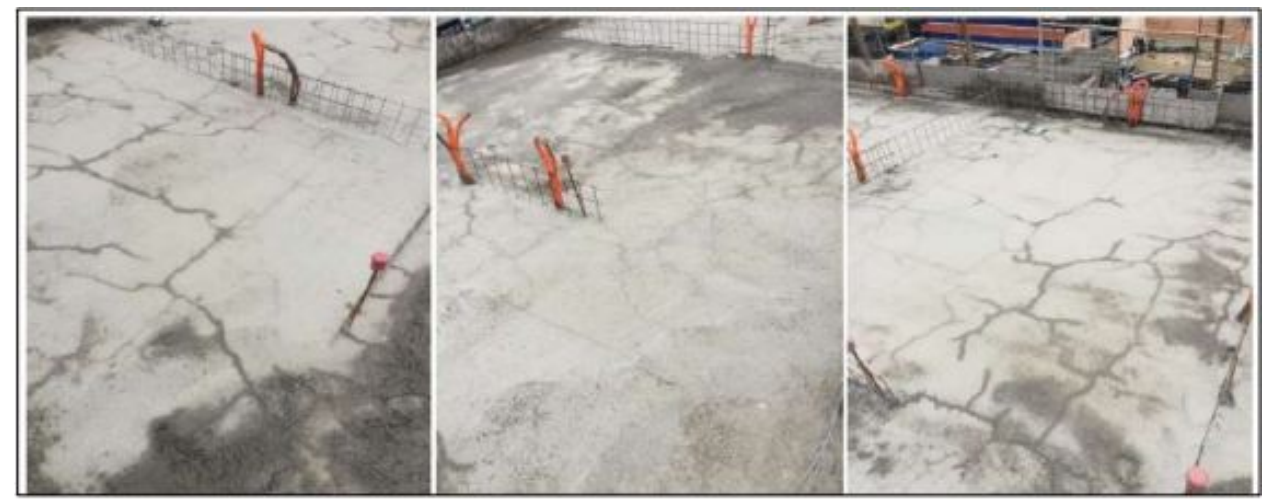

Figura 7. Fissuração mapeada verificada em lajes da Obra B.

\subsubsection{Causas}

As prováveis causas da fissuração de paredes e lajes são a retração térmica e hidráulica. A retração térmica assume valores elevados nas primeiras idades do concreto, o que explica o fato destas fissuras terem sido observadas nos primeiros dias após a concretagem (Gonçalves, 2015). A retração hidráulica se dá devido à redução do volume do concreto, à medida em que o processo de hidratação avança e parte da água evapora (Recena e Antônio, 2014). As fissuras assim formadas apresentam aspecto característico de "mapas", conforme observado na Figura 7. Verificou-se que, em ambas as obras analisadas, tal retração e fissuração foram mais acentuadas, devido à cura insuficiente dos elementos estruturais. Além disso, a parede de concreto trabalha como um sistema monolítico, de modo que as forças de tração atuam de maneira desigual no elemento quando da presença de vãos (portas e janelas), o que comumente leva à formação de fissuras nas regiões de cantos, os quais concentram boa parte das tensões (Carmona, 2013).

A análise detalhada do projeto estrutural da Obra B revelou a inexistência de armaduras de reforço nos cantos de janela, sendo este um fator crítico para o aparecimento das fissuras. Deste modo, o projeto não observou o prescrito na NBR 16055 (ABNT, 2012), a respeito do uso de armaduras de reforço em aberturas e quinas. Por outro lado, o projeto estrutural da Obra A, que contemplava reforços nos cantos de janelas, também apresentou fissuras nestes locais, porém em menor quantidade que a obra B. Neste último caso, o posicionamento incorreto desses reforços foi o ponto crítico para o aparecimento das fissuras.

A causa das fissuras verticais ao longo da extensão de algumas paredes foram causados por eletrodutos instalados em seu interior e o fato destes elementos estruturais terem sido executados com cobrimento insuficiente.

\subsubsection{Diagnóstico}

Segundo a NBR 6118 (ABNT, 2014), o limite máximo de abertura de fissura em estruturas de concreto expostas a ambiente agressivo Urbano (classe II), é $0,3 \mathrm{~mm}$. Deste modo, as fissuras verticais nas paredes, de cantos de janela ou lajes devem ser tratadas superficialmente, a fim de 
garantir a manutenção da vida útil dos elementos de concreto, protegendo as armaduras de processos corrosivos.

\subsubsection{Tratamento}

As fissuras devem ser abertas a uma largura e profundidade de $5 \mathrm{~mm}$, com o uso de serra circular ou equipamento similar; em seguida, devem ser preenchidas com selante, o qual é injetado com bico próprio; aplica-se, então, uma demão cheia de impermeabilizante, com o auxílio de um pincel 4", sem diluições; coloca-se, então, uma tela de poliéster com largura de $10 \mathrm{~cm}$, a qual deve ser bem esticada sobre a fissura; após a secagem do produto, aplica-se a segunda demão de impermeabilizante, de modo que a tela seja completamente envolvida por ele. A Figura 8 apresenta o aspecto de uma fissura tratada.

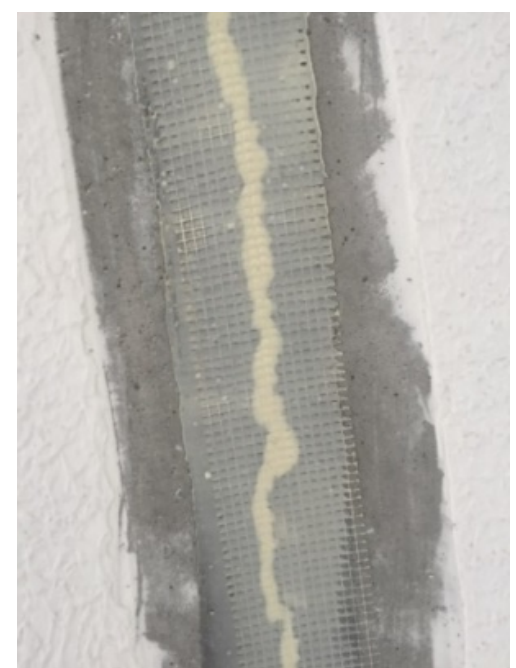

Figura 8. Tratamento de fissura de parede de concreto na Obra A com aplicação de selante, impermeabilizante e tela de poliéster.

\subsection{Segregação do Concreto e Vazios de Concretagem}

Tanto na Obra A quanto na Obra B foi verificada segregação do concreto em diferentes pontos dos elementos de paredes de concreto, conforme observado na Figura 9. Além destas, evidenciouse, em ambas as obras, a presença de vazios de concretagem, sobretudo na região inferior das janelas, com nichos no formato de V (Figura 10a). A situação mais crítica ocorreu na Obra B, na qual, durante a desforma de uma parede de divisa, notou-se que grande parte do elemento não havia sido concretada, originando um grande nicho de concretagem (Figura 10b).

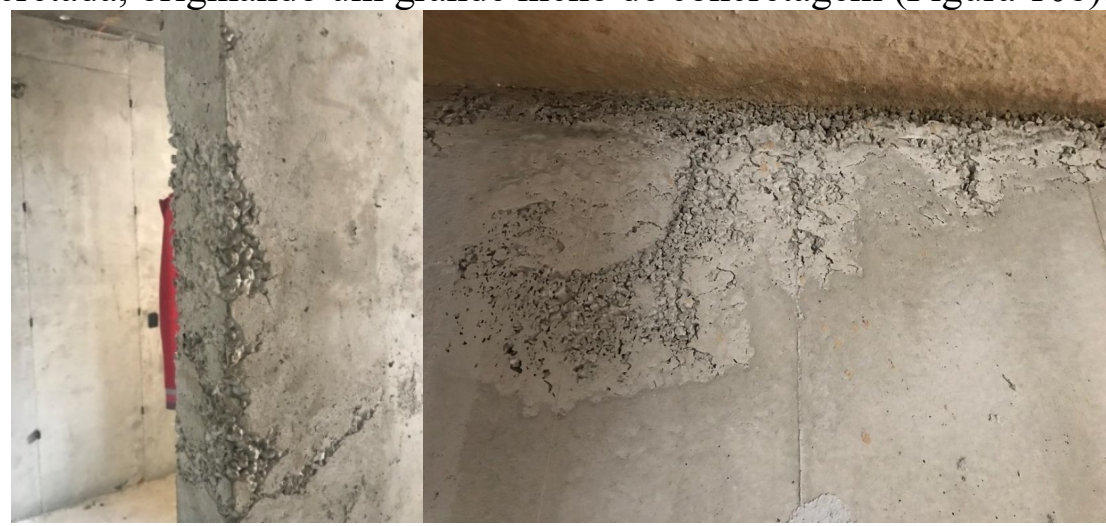


(a)

(b)

Figura 9. Segregação do concreto de parede na região do vão de porta (a) e no topo de parede (b) na Obra B.

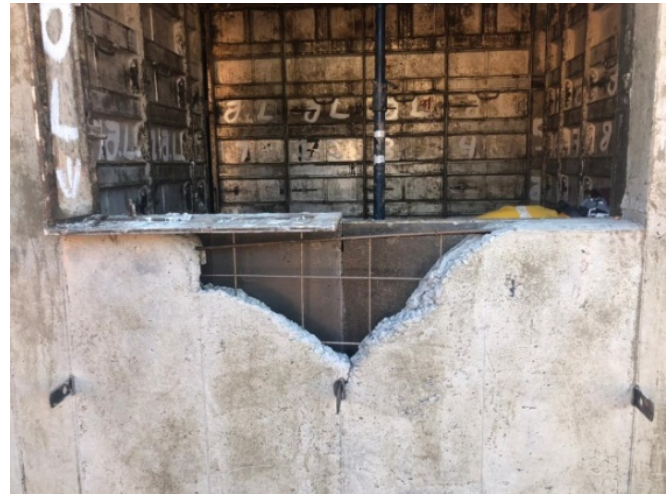

(a)

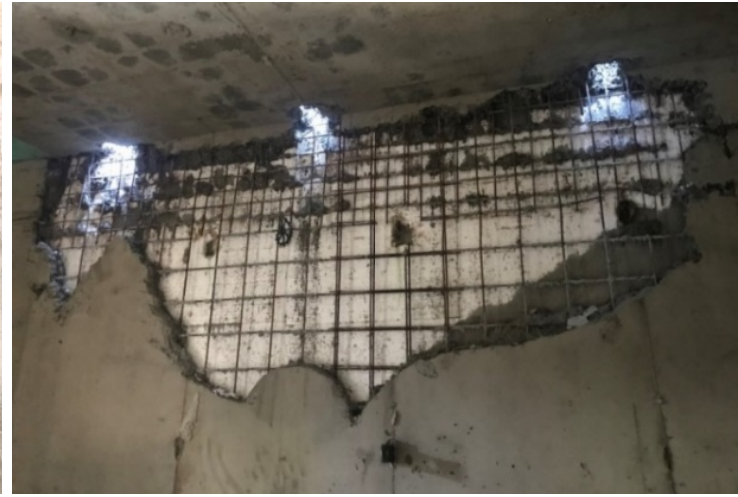

(b)

Figura 10. Nicho de concretagem em formato $\mathrm{V}$ sob vão de janela em parede de concreto na Obra A (a) e grande falha de concretagem na parte superior de parede na Obra B (b).

\subsubsection{Causas}

As causas da segregação e dos vazios de concretagem estão relacionadas ao transporte e lançamento do concreto (Bellei, 2015; Careli e Tcath, 2017). Tanto na Obra A quanto na Obra B foi necessário, em algumas situações, posicionar a bomba lança a uma altura superior a $2 \mathrm{~m}, \mathrm{o}$ que aumentou as chances de segregação. Esta altura de lançamento foi utilizada devido às dificuldades de acesso a alguns locais no momento da concretagem. De acordo com Aoki (2007), a altura de concretagem influencia no surgimento de vazios, uma vez que os materiais que compõem o concreto possuem diferentes massas específicas e tendem a se separar quando em queda livre. Deste modo, Fonseca Jr. (2008) complementa que não se deve lançar o concreto a uma altura superior a $2 \mathrm{~m}$.

Outro ponto diz respeito ao Slump do concreto no momento de seu lançamento. As especificações de projeto previam um concreto com Slump de $22 \pm 3 \mathrm{~cm}$. Para melhorar a trabalhabilidade, foi acordado, entre projetistas e executores, realizar o aumento do Slump para $25 \pm 3 \mathrm{~cm}$. Porém, em alguns casos, ocorreram erros de dosagem, de modo que o concreto chegou à obra com Slump de $22 \mathrm{~cm}$. Em outros casos, verificou-se que o Slump de $25 \mathrm{~cm}$ era reduzido pouco tempo após o início da concretagem. Um exemplo disto foi um concreto cujo Slump inicial era de $27 \mathrm{~cm}$, tendo sido reduzido para $23 \mathrm{~cm}$ após 5 min do começo da concretagem. Por este motivo, tais concretos foram equivocadamente vibrados, o que culminou no surgimento de nichos de concretagem. Somando-se a isso, verificou-se a ocorrência de problemas mecânicos na bomba de lançamento. Assim, a frequente interrupção da concretagem para realização de manutenção na bomba modificava o Slump inicial, reduzindo-o e comprometendo a trabalhabilidade da mistura.

\subsubsection{Diagnóstico}

As manifestações patológicas de segregação do concreto e vazios de concretagem podem ser consideradas críticas, uma vez que, dependendo da profundidade da segregação e da extensão do vazio, há evidente redução da resistência mecânica do elemento estrutural. Além disso, conforme observado na Figura 10, há clara exposição das armaduras, o que levará a um processo de 
corrosão precoce, comprometendo a resistência e a durabilidade da parede. Por isso, faz-se corrigir estas anomalias o quanto antes.

\subsubsection{Tratamento}

Para tratar os vazios de concretagem e a segregação do concreto, faz-se necessário avaliar, primeiro, sua gravidade. Vazios com cavidades até $3 \mathrm{~cm}$ são considerados pequenos. Nestes casos, procede-se à escarificação do local e remoção do concreto segregado, seguida de recomposição do local com o mesmo concreto utilizado na concretagem das paredes ou com graute de mesma resistência. No caso de grandes vazios de concretagem, como o da parede da Figura 10b, cuja resistência mecânica foi gravemente prejudicada, faz-se necessário demolir e refazer a peça.

\subsection{Espessura Insuficiente de Cobrimento das Armaduras}

Em ambas as obras foram constatadas falha na espessura de cobrimento das armaduras, sobretudo no que diz respeito à tela utilizada na laje e nas paredes, nos pontos de travamento das instalações elétricas e hidráulicas. Tais falhas se tornaram evidentes, podendo ser observadas na parte externa dos elementos estruturais, conforme observado na Figura 11.

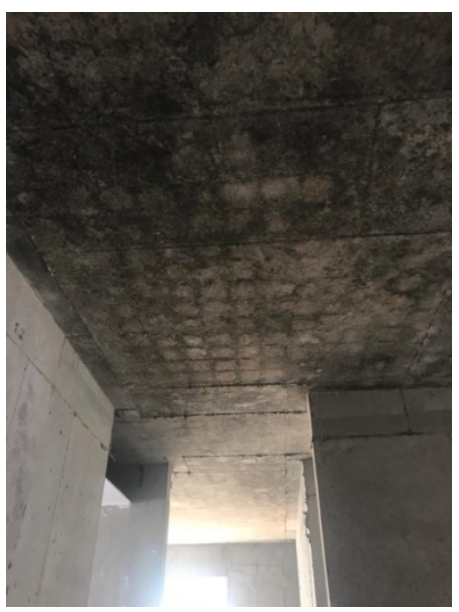

(a)

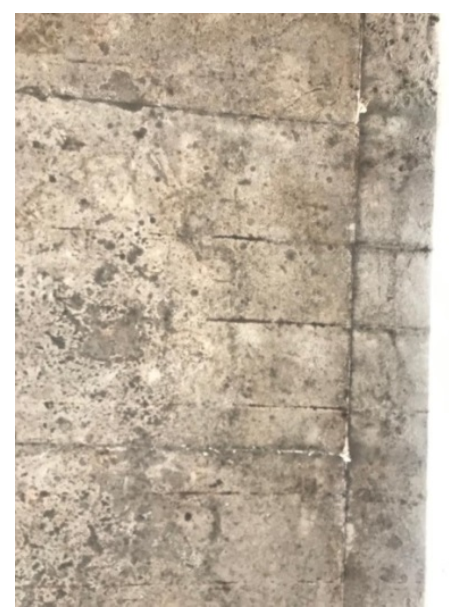

(b)

Figura 11. Cobrimento insuficiente das armaduras no fundo de laje (a) e em parede (b) da Obra A.

\subsubsection{Causas}

A NBR 6118 (ABNT, 2014) define os cobrimentos mínimos das armaduras de acordo com a classe de agressividade do meio em que elas se encontram. Ambos os empreendimentos se enquadram na classe de agressividade II, ambiente urbano, cujo cobrimento mínimo dos elementos estruturais é $2 \mathrm{~cm}$.

Nas lajes de ambas as obras foram utilizados espaçadores de $2 \mathrm{~cm}$ de altura para armação positiva e de $8 \mathrm{~cm}$ para a armação negativa. Para o cobrimento das paredes, considerando que a estrutura faz uso de telas, foram introduzidos espaçadores circulares nos eixos das paredes, com diâmetro igual à largura da parede, isto é, $10 \mathrm{~cm}$.

Entretanto, a análise in loco revelou que, nas duas obras, a quantidade de espaçadores definida nem sempre foi atendida, criando pontos de contato entre a armação e a forma da laje. Além 
disso, o processo de montagem da armação da laje foi feito simultaneamente à instalação dos eletrodutos e dos passantes na laje, a partir da seguinte ordem: instalação da armação negativa, instalação dos eletrodutos e caixas embutidas, posicionamento dos passantes, e instalação da armação positiva. Devido ao processo de montagem, o fluxo de pessoas sobre a armação positiva causou o deslocamento e a quebra de vários espaçadores, os quais não foram substituídos. Além disso, durante o processo de concretagem, o mesmo aconteceu com os espaçadores da armação negativa, uma vez que havia circulação da equipe de concretagem sobre a armação concluída. A armação utilizada para travamento das caixas elétricas não respeitou o cobrimento mínimo definido, uma vez que foram posicionadas próximas à superfície da parede.

\subsubsection{Diagnóstico}

O cobrimento é a proteção física da armadura e, quando executado com espessura insuficiente, pode comprometer a durabilidade das peças estruturais, expondo as armaduras a um processo de corrosão precoce. Com o tempo, a corrosão das armaduras comprometerá a resistência mecânica dos elementos. Deste modo, a manifestação patológica é considerada crítica, devendo ser reparada.

\subsubsection{Tratamento}

Para o tratamento, propõem-se retirar o concreto de cobrimento, verificando a existência de possíveis pontos de corrosão das armaduras. Naquelas em que já for possível observar um processo precoce de corrosão, prosseguir à completa limpeza das barras com lixa ou escova de aço, removendo-se, para isto, cerca de $2 \mathrm{~cm}$ do concreto situado ao redor delas. Em seguida, realizar a passivação das armaduras, por meio da aplicação de produtos à base de zinco e/ou cimentícios. Fazer, então, ponte de aderência cimentícia ou epoxídica e fechar o elemento com graute, utilizando-se fôrmas, a fim de garantir uma espessura adequada de cobrimento (SOUZA e RIPPER, 1998; MARQUES, 2015).

\subsection{Análise dos Resultados}

A Tabela 3 apresenta um resumo das manifestações patológicas encontradas nas Obras A e B, tal como sua fonte originária. Nota-se que a principal origem das anomalias foi à etapa de execução, seguida por falhas nos materiais utilizados e no projeto.

Tabela 3. Análise das Principais Manifestações Patológicas nas Obras A e B.

\begin{tabular}{|l|l|l|c|}
\hline Manifestação Patológica & $\begin{array}{c}\text { Ocorrência } \\
\text { na Obra A }\end{array}$ & $\begin{array}{c}\text { Ocorrência } \\
\text { na Obra B }\end{array}$ & Causas \\
\hline Descolamento Cerâmico & & & Execução \\
\hline $\begin{array}{l}\text { Fissuras em Cantos de Janelas, na } \\
\text { Extensão das Paredes e nas Lajes }\end{array}$ & & & Projeto e Execução \\
\hline Segregação de Concreto & & & Execução e Material \\
\hline Vazios de Concretagem & & & Execução e Material \\
\hline Falha no Cobrimento da Armadura & & & Execução \\
\hline
\end{tabular}






Dentre as manifestações patológicas identificadas e analisadas no estudo, somente o descolamento cerâmico foi mitigado na Obra B. Neste sentido, a avaliação dos serviços preliminares, o treinamento da equipe de obra e a fiscalização do serviço foram fundamentais para prevenir as anomalias.

Com respeito à fissuração, constatou-se que a ausência de previsão de reforço nos cantos das paredes no projeto da Obra $\mathrm{B}$ culminou num maior número de fissuras que na Obra $\mathrm{A}$. Neste sentido, conclui-se que houve um erro de projeto na Obra B, o qual não foi questionado pela equipe executora. Por sua vez, na Obra A foram constatadas falhas no treinamento da equipe de obra e na fiscalização do serviço, uma vez que, em alguns casos, a armadura de reforço foi posicionada de maneira incorreta. As fissuras verticais, observadas de maneira especial na Obra A, levantam questões a respeito da necessidade de compatibilidade entre os projetos estruturais, arquitetônicos e de instalações, de maneira a prever reforços em paredes de grande comprimento que possuam muitos eletrodutos embutidos. Tais reforços se mostram particularmente importantes nos pavimentos inferiores, nos quais a intensidade das cargas de compressão atuantes é maior (Machado e Filho, 2015). Por fim, as fissuras verificadas nas lajes ressaltam a importância de se realizar um processo de cura adequado, sobretudo em concretagens realizadas em dias muito quentes.

A segregação do concreto e os vazios de concretagem são falhas conjuntas da execução e do material utilizado. Os erros de dosagem do concreto, combinados às interrupções da concretagem devido a problemas com a bomba, e equivocadamente contornados pela adição de água, denunciam uma grande falta de controle tecnológico na etapa de concretagem. O lançamento do concreto a alturas superiores a $2 \mathrm{~m}$ também contribui para a segregação do material e com a formação de nichos de concretagem. Deste modo, reforça-se a necessidade de se aplicar programas de treinamento mais rigorosos à equipe de obra, dos quais pode depender a qualidade final dos elementos concretados.

A espessura insuficiente do cobrimento das armaduras também é resultado de falhas na execução. Neste caso, muitos espaçadores foram quebrados ou deslocados pela mão-de-obra durante a realização dos demais serviços, não tendo sido repostos. Novamente, o treinamento rigoroso da mão-de-obra de mostra fundamental para evitar futuras manifestações patológicas.

Entende-se que, mesmo manifestações patológicas com baixo risco à segurança estrutural causam retrabalhos e prejuízos financeiros à empresa. Dessa forma, em obras com o sistema de paredes de concreto, se faz necessária uma melhor gestão de projetos do empreendimento previamente à execução dos serviços, escolhendo de forma mais assertiva os fornecedores e compatibilizando os projetos. Por fim, o treinamento da mão de obra, tanto da equipe de montagem quanto dos responsáveis pela conferência do serviço, é de suma importância para a diminuição da incidência dessas manifestações patológicas.

\section{CONCLUSÕES}

O sistema construtivo de paredes de concreto proporciona alta produtividade à obra, otimizando tempo e custos na construção civil. Entretanto, com base nos estudos de caso realizados nas Obras 
A e B, percebe-se que o método pode estar sujeito a gargalos, os quais podem comprometer a qualidade do produto final.

Grande parte das falhas construtivas está relacionada à etapa de execução, o que evidencia a necessidade que tal sistema apresenta de um treinamento rigoroso e eficaz da mão-de-obra, aliado a uma contínua fiscalização dos serviços. Outro ponto importante diz respeito à logística da concretagem, cujas etapas devem ser previamente planejadas e interconectadas, sendo necessária a participação síncrona dos diferentes agentes, desde os fornecedores das concreteiras à equipe de recebimento do concreto e à equipe de concretagem.

Por fim, tal como foi feito com o descolamento cerâmico, presente na Obra A e mitigado na Obra B, estimula-se a realização de fiscalizações que visem proporcionar aprendizado e melhorias, a fim de que os erros cometidos no passado não se repitam no futuro.

\section{AGRADECIMENTOS}

Os autores agradecem o suporte financeiro do Centro Federal de Educação Tecnológica de Minas Gerais (CEFET-MG) e das agências de fomento CNPq, CAPES e FAPEMIG.

\section{REFERÊNCIAS}

Associação Brasileira de Cimento Portland. (2008), "Parede de Concreto - Coletânea de Ativos". São Paulo.

Associação Brasileira de Normas Técnicas. (2012). NBR 16055: Paredes de Concreto Moldada no Local para a Construção de Edificações - Requisitos e Procedimentos. Rio de Janeiro.

Associação Brasileira de Normas Técnicas. (2004). NBR 6118: Projeto de Estruturas de Concreto - Procedimento. Rio de Janeiro.

Associação Brasileira de Normas Técnicas. (1996). NBR 13753. Revestimento de piso interno ou externo com placas cerâmicas e com utilização de argamassa colante - Procedimento. Rio de Janeiro.

Associação Brasileira de Normas Técnicas. (1995). NBR 13528. Revestimento de paredes e tetos de argamassas inorgânicas - Determinação da resistência de aderência à tração. Rio de Janeiro.

Associação Brasileira de Normas Técnicas. (2005). NBR 14081. Argamassa colante industrializada para assentamento de placas cerâmicas. Requisitos. Rio de Janeiro.

Associação Brasileira de Normas Técnicas. (2012). NBR 16055: Parede de concreto moldada no local para a construção de edificações - Requisitos e procedimentos. Rio de Janeiro.

Aoki, J. Proteja o seu concreto. Massa Cinzenta, Curitiba. Disponível em: $<$ http://www.cimentoitambe.com.br/proteja-seu-concreto-3/>. Acesso em: 22 mai. 2021.

Bellei, E. (2015), "Influência do uso de adição do fino de areia de descarte de fundição (ADF) no controle de exsudação e segregação de concretos autoadensáveis”, Trabalho de Conclusão de Curso (Graduação), Universidade Tecnológica Federal do Paraná, Pato Branco, 108 f.

Braguim, T. C., Bittencourt, T. N. (2014), Dimensionamento de paredes de concreto armado moldadas no local para a máxima tensão normal de compressão. IBRACON de Estruturas $e$ Materiais. 7(3):498-533. 
Carelli, J., Tcatch, R. (2017). “Avaliação da influência da altura de lançamento do concreto na sua resistência à compressão”, Anuário Pesquisa e Extensão Unoesc Joaçaba, v. 2. ISSN 26254665 .

Carmona, T. G., Carmona, A. F. (2013). "Fissuração nas estruturas de concreto", Boletín Técnico, Congresso ALCONPAT Internacional, Mérida: CDMX (MÉXICO), p. 18.

Corrêa, J. M. (2012) "Considerações sobre projeto e execução de edificios em paredes de concreto moldados in loco", Trabalho de Conclusão de Curso, Departamento de Engenharia Civil, Universidade Federal de São Carlos.

Dornelles, K. A., Oliveira, L. S. (2012) "Sistema construtivo em paredes de concreto moldadas no local" Instituto de Arquitetura e Urbanismo, Universidade de São Paulo.

Fonseca Júnior, A. (2008) “Paredes de concreto no cenário atual da construção civil”, Concrete Show 2009, São Paulo.

Gonçalves, E. A. B. (2015), “Estudo de patologias e suas causas nas estruturas de concreto armado de obras de edificações", Trabalho de Conclusão de Curso (Graduação), Universidade Federal do Rio de Janeiro, p. 174.

Marques, V. S. (2015), "Recuperação de estruturas submetidas à corrosão de armaduras: definição das variáveis que interferem no custo", Trabalho de Conclusão de Curso (Graduação), Universidade Federal do Rio Grande do Sul, p. 104.

Missurelli H., Massuda C. (2009), “Como construir Paredes de Concreto”, Revista Téchne. 147, (17):74-80.

Monge, R. (coord.) (2013) "Coletânea de Ativos Parede de Concreto 2011/2013". Disponível em: https://www.solucoesparacidades.com.br/wpcontent/uploads/2020/08/Coletanea_PC2013.pdf

Recena, P., Antonio, F. (2014), "Retração do Concreto”. 1 ed. Porto Alegre: Editora Universitária da PUCRS.

Souza, V. C. M., Ripper, T. (1998), "Patologia, recuperação e reforço de estruturas de concreto". 1 ed. São Paulo: Pini. 